\title{
UN EJEMPLO DE APROPIACIÓN SEMÁNTICA DE LA ICONOGRAFÍA IMPERIAL EN EL SIGLO VI: EL TEMA DE LA ASCENSIÓN DE CRISTO”
}

\section{CARLES BUENACASA, MARTA FERNÁNDEZ LAHOSA, CARLES MANCHO}

UDC: $7.046 .3: 27-31 " 01^{\prime \prime}$

Original scientific paper

Manuscript received: 05. 12. 2016.

Revised manuscript accepted: 24. 04. 2017.

DOI: 10.1484/J.HAM.5.113756

\author{
C. Buenacasa \\ M. Fernández Lahosa \\ C. Mancho \\ Instituto de Investigación en Culturas Medievales (IRCVM) \\ Universitat de Barcelona, Facultat de Geografia i Historia \\ Montalegre, 6, o8ooı Barcelona, España
}

The iconography of the Ascension of Christ, is a recurring theme in numerous supports, monumental or not in the late antiquity. This image of the triumph of the God-Man over death was forged during the fourth and fifth centuries, clearly in imitation of the parallel concept of imperial apotheosis. However, it is during the sixth century that, in Eastern territories, it assumes the formal characteristics that will define the iconographic model of the following centuries. On the one hand, our target is to highlight the precedents that give rise to this iconographic type in the sixth century and to justify the reasons why the theme of the Ascension reaches its maturity in that century in the East while in the West the theme seems to fall. On the other hand, we would like to emphasize the context and the ideological sources that explain both the late appearance of the subject at the end of the fourth century, as well as its importance in the struggles for the definition of an orthodoxy boosted but not always controlled by the imperial court.

Keywords: Ascension of Christ; Apotheosis; Early Christian Iconography; Late Antiquity Art., dextera Domini, Saint Apollon of Bawit, Ascension of Eliah, Oriental typology

El análisis del nacimiento y desarrollo de la iconografía cristiana resulta una cuestión no exenta de dificultades metodológicas, pues se corre el riesgo de falsear involuntariamente las conclusiones a partir de presupuestos conceptuales inexactos. Esta situación es, sin lugar a dudas, lo que, desde el nacimiento del interés por el primer arte cristiano, comportó la oposición antitética entre cristianos y romanos en los estudios. Si bien esta posición, en buena medida, se halla ya superada, no está de más recordar el hecho, pues la persistencia de este apriorismo conceptual sigue aún presente en un terreno de estudio, el de la historia del arte, en que se siguen mezclando ciencia y fe, con resultados desastrosos para la primera.

En este sentido, la afirmación de que la historia la escriben los vencedores a menudo ha sido olvidada al enfrentarse con estos temas de investigación. Paradójico, si consideramos que la victoria del cristianismo antiguo frente al resto de confesiones religiosas del Imperio romano, especialmente en lo referente al control del poder, ha sido la más contundente y duradera de todas ellas. Así pues, exceptuando el porcentaje atribuible a los descubrimientos arqueológicos de todo tipo y el correspondiente a lo que el azar y la fortuna han permitido preservar, seguimos disponiendo mayoritariamente del material artístico que la Iglesia, a lo largo de los 1.700 años que nos separan del Edicto de Tolerancia, fue decidiendo que pudiéramos disponer.

En este contexto debemos aceptar que la información a nuestro alcance es una documentación muy manipulada que tiende a ocultar algo que ya de por sí es oscuro en cualquier contexto: los orígenes. Especialmente si, como sucede en nuestro caso, los orígenes suponen una adaptación Lampedusiana del contexto de nacimiento, esto es, el Imperio romano precristiano. Así pues, no estará de más recordar: a) que el cristianismo es una religión romana, una de las muchas que se desarrollaron en los tiempos del Imperio, de origen oriental, y más concretamente la última religión que adquirió rango de oficialidad en la historia imperial; b) que el hecho religioso en la antigua Roma, al margen de las implicaciones cultuales y culturales presentaba una vertiente jurídica estructural en la sociedad romana; c) y por ello mismo es imposible entender aspecto alguno del desarrollo del cristianismo dentro del Imperio sin entender su relación con el poder.

El objetivo de nuestro trabajo es analizar el nacimiento de una iconografía concreta, la Ascensión de Cristo, a partir de estas premisas. Se trata de una temática artística que nos ha de permitir, en un cierto sentido, someter a revisión metodológica el enfoque del estudio de la producción artística romano-cristiana a partir de las premisas metodológicas que acabamos de enunciar.

\section{LA ICONOGRAFÍA DE LA ASCENSIÓN}

Para realizar nuestra investigación, conservamos un número de piezas limitado, 26 en total, cuya cronología se extiende entre finales del siglo IV, período en que se acostumbran a datar los dos sarcófagos procedentes de Arlés, y el 586, año en que se fecha, aproximadamente, el evangeliario de Rábula. Una simple aproximación preliminar a estas piezas permite detectar ciertos elementos que destacan a primera vista.

El primero es que seis de ellas, procedentes de Oriente, son de tipo monumental; se trata de cinco ábsides y del dintel de al-Mualaca, un elemento de madera, identificado con esta función arquitectónica, sin que pueda precisarse su ubicación en la iglesia cairota del mismo nombre. Por lo que se refiere a los cinco ábsides, cabe destacar que provienen de un mismo lugar, el monasterio de San Apolo en Bawit ${ }^{1}$,

*Este artículo forma parte de las investigaciones realizadas dentro del grupo ArsPicta para los proyectos PRECA (HAR 2013-42017-P) del Ministerio español de Economía y Competitividad, y CROMART (no proyecto 6095) de la Hrvatska zaklada za znanost.

${ }^{1}$ M. RASSART-DEBERGH, Répresentation d'Apôtres aux Kellia, in Journal of Coptic Studies, 2, 1992, p. 29-42, DOI : 10.2143/JCS.2.0.583381. 
un monasterio de importancia local, y que comparten un mismo contexto cronológico, los siglos VI-VII. Sin entrar ahora de pleno en el análisis de la iconografía que reflejan, puede avanzarse, que ésta es híbrida y sobre todo que, por lo que a la Ascensión se refiere, esta temática iconográfica se muestra de manera idéntica en todos los casos. Es por ello que, en realidad, si en vez de cinco ejemplares sólo se hubiera conservado uno, poco cambiaría cualitativamente la información que de estos ábsides se desprende en lo concerniente a la difusión iconográfica del tema, a las particularidades de su concepción o al mensaje contenido.

El segundo elemento que destaca es que, en lo referente a las piezas de procedencia occidental, solamente dos pueden ser consideradas monumentales, si bien ambas forman parte de un ciclo en que comparten espacio con otras escenas. Una es el panel de las puertas de Santa Sabina (Roma) dedicado a la Ascensión (mediados s. V) y la otra se halla en una de las columnas del baldaquino de San Marco en Venecia ${ }^{2}$. En ambos casos, se trata de escenas difícilmente perceptibles por sus dimensiones y por el contexto en que se exhibían³. Más allá, pues, de la importancia objetiva de la iconografía que reflejen ambos ejemplos es evidente que el impacto in situ de su visión estaba muy condicionado por las condiciones objetivas de exposición.

Tercera constatación, y retornando a Oriente, diez de las piezas conservadas son ampullae procedentes de Tierra Santa, datadas en el siglo VI. A estos objetos puede aplicarse el mismo razonamiento que a los ábsides de Bawit: que sean diez o que fuera una no altera nuestra información sobre el contexto de origen, posiblemente, la Jerusalén del siglo VI.

La cuarta y última consideración preliminar es que todas las piezas que proceden de Oriente y que han podido ser fechadas con una cierta seguridad son del siglo VI o de cronologías posteriores, con excepción del dintel de al-Mualaca, dotada de una inscripción que la dataría en el siglo IV, aunque la cronología de esta pieza ha sido muy discutida ${ }^{4}$.

Con respecto a la iconografía, de manera genérica, puede decirse que todas estas imágenes contienen elementos coincidentes. En primer lugar, la figura de Cristo quien, de una forma u otra, asciende. Y, en segundo lugar, los testigos, constituidos por un número variable de discípulos. En algunos casos, la Virgen aparece y, en otros, está ausente.

Veamos algunos ejemplos: en los sarcófagos de Servannes y de Clermont-Ferrand, datados a finales del siglo IV, Cristo sube una pendiente montañosa mientras es observado por tres o cuatro apóstoles en actitud expresiva. Una composición similar presenta la Ascensión de la Reidersche Tafel (ca. 400), conservada en el Bayersiches Nationalmuseum de Munich (fig. 1), donde se puede observar la aparición de la dextera Domini, que toma por la muñeca al Cristo ascendiente. El relicario de San Quirico y Julita de Rávena (ca. siglo V) muestra una composición singular, puesto que los testigos no son los apóstoles sino las Marías (igualmente presentes, en asociación con los apóstoles, en la tabla de Munich. Otra composición especial es la esculpida en las ya mencionadas puertas lígneas de Santa Sabina de Roma, también del siglo V, donde Cristo es conducido a los cielos por dos ángeles mientras una tercera figura angelical y cuatro apóstoles dan testimonio de la escena.

En lo que se refiere a Oriente, y ya en el contexto del siglo VI, los ejemplos con los que se cuenta, por orden cronológico, son: el relicario del sancta sanctorum Lateranense, conservado en el Vaticano; el anillo palestino conservado en el Walters Art Museum de Cleveland; el icono conservado en Santa Catalina del monte Sinaí; y las ampullae de Tierra Santa. Estas últimas presentan una composición muy similar entre sí, mostrando a Cristo entronizado en el interior de una mandorla sustentada por dos o cuatro figuras angélicas, ascendiendo a los cielos bajo la mirada de los doce apóstoles que flanquean la figura de la Virgen, en la mayoría de los casos, en actitud orante. A este elenco de piezas se añaden las cinco capillas del monasterio de San Apolo de Bawit, con una estructura muy parecida a la de las ampullae, aunque con pequeñas variantes compositivas como son: la presencia de los cuatro vivientes y las ruedas de fuego del carro de la visión de Ezequiel en el trono de Cristo. Pero sin duda, el ejemplo más completo y fiel a la narración del texto bíblico de los Hechos de los apóstoles es el evangeliario de Rábula, que añade a la composición dos ángeles que ofrecen coronas a Cristo y dos que advierten de su regreso a los apóstoles 5 .

Lógicamente, las formas que adoptan estas representaciones están justificadas en parte por las fuentes cristianas, oficiales o no, que nos describen el hecho en sí. Entre las oficiales, cabe destacar los evangelios neotestamentarios, ya que de los cuatro, el único que no hace referencia alguna a la Ascensión es el de Mateo. En Juan, se menciona sólo su subida a los cielos y el episodio se relaciona con la aparición de Jesús a María Magdalena en el famoso episodio del noli me tangere ${ }^{6}$. En Marcos, se apunta que, tras su Ascensión, Cristo se sentó a la derecha del Padre ${ }^{7}$, idea que se recupera

\footnotetext{
${ }^{2}$ Aunque estos dos testimonios se conservan en Occidente, se han postulado conexiones con talleres orientales en algunos aspectos. En referencia a la columna, ésta habría sido ubicada en la catedral de San Marco en el siglo XIII, pero su realización podría haberse llevado a cabo en Rávena o en Oriente. Con respecto a las puertas de Santa Sabina, se ha propuesto que fueran de confección oriental (F. CABROL - H. LECLERQ, Ascension, in Eidem (dir.), Dictionnaire d'archéologie chrétienne et de liturgie, I/2, París, 1907, col. 2.987-2.888; T. WEIGEL, Le colonne del ciborio dell'altare maggiore di San Marco a Venezia: nuovi argomenti a favore di una datazione in epoca protobizantina, Venezia, 2000).

${ }^{3}$ Recientement I. Foletti ha sostenido que no se trate de una Ascensión sino de la Asunción de Enoc, vid. I. FOLETTI, M. GIANANDREA, Zona liminare. Il nartece di Santa Sabina a Roma, la sua porta e l'iniziazione cristiana, Roma, 2015, p. 119-122, 167-172. Vease, ahora, para la interpretación general de la puerta así como para la visibilidad de la escena en el contexto.

${ }^{4}$ En opinión de M. Sacopoulo, la datación contenida en la inscripción permite datar la fabricación del dintel entre el 335/336 y el 431 (M. SACOPOULO, Le linteau copte dit d'Al-Moâllaka, in CArch 9, Paris, 1957, p. 10o). En cambio, H. L. Kessler, a partir del griego de la inscripción, data esta pieza en el siglo VI (H. L. KESSLER, Narrative representations, in K. Weitzmann (ed.), Age of spirituality: late antique and early Christian art, New York, 1980, p. 502). Por su parte, E. T. Dewald ha sido el primero en datar su creación en el siglo VIII, en función de paralelos estilísticos y conceptuales (E. T. DEWALD, The Iconography of the Ascension, in AJA 19/3, Princeton, 1915, p. 291). La cronología de Sacopoulo es la más seguida por la historiografía, por ejemplo, por Y. CHRISTE, Les grands portails romans: études sur l'iconologie des théophanies romanes, Genève, 1969, p. 68; V. M. SCHMIDT, Ascensione, in Autores diversos (dir.), Enciclopedia dell'arte medievale, II, Roma, 1991, p. 574.

${ }^{5}$ El evangelio de Rábula, conservado en la Biblioteca Medicea Laurenziana de Florencia con la cota, Plut. 1. 56, es un manuscrito procedente de Síria donde fuera realizado entorno al 556. En el fol. 13v se encuentra la imagen de la Ascensión de Cristo. Acutualmente, el manuscrito con el código IT:FIo10o_Plutei_01.56 ha sido digitalizado y se puede consultar en la página: http://mss.bmlonline.it/s.aspx?Id=AVg6N26nADdoerJpIyzg\#/oro/38 ${ }^{6}$ Jn. $20,17-18$.

${ }_{7}$ Mc. 16, $19-20$.
} 
en otros momentos del Nuevo Testamento ${ }^{8}$, pero que debe su prefiguración a algunos salmos tales como el 24 (23) y, en especial, el 110 (109). Finalmente, en Lucas, se menciona la acción de bendición a los apóstoles durante su ascenso9.

La descripción más completa de la Ascensión en el Nuevo Testamento se encuentra en los Hechos de los apóstoles, que narra la aparición de dos ángeles que dicen a los apóstoles: hic Iesus, qui assumptus est a uobis in caelum, sic ueniet quemadmodum uidistis eum euntem in caelum ${ }^{10}$. Mediante estas palabras se alude a la segunda venida de Cristo, y a las imágenes visionarias y apocalípticas que la prefiguran como un referente para crear la iconografía de la Ascensión, tales como los relatos del apocalipsis ${ }^{11}$, las visiones de Isaías ${ }^{12} \mathrm{y}$ las de Ezequiel' ${ }^{13}$.

Entre las fuentes no oficiales, o apócrifas, resultan de especial interés las diferentes versiones de las actas de Pilato. En la "versión griega A", Cristo sube a los cielos en medio de una nube, mientras que en la "versión griega B" asciende por sus propias fuerzas ${ }^{14}$. No obstante, ambos textos coinciden en el reducido número de apóstoles que le acompañan y en sus actitudes de sorpresa, que les llevan a cubrirse el rostro o a tirarse al suelo, y que pueden vincularse a composiciones precedentes, tales como la de la Reidersche Tafel (ca. 40o) (fig. 1) o las puertas de Santa Sabina (mediados del s. V) ${ }^{15}$. También interesante es el evangelio apócrifo de Pedro, que indica la Ascensión de Cristo a los cielos justo después de su resurrección por las alusiones de un personaje celestial ${ }^{16}$.

Sin embargo, con excepción de los Hechos de los Apóstoles, son pocos los textos evangélicos (tanto canónicos como apócrifos) que brindan detalles sobre la subida de Cristo a los cielos. Si bien todos ellos subrayan la ascensión junto al Padre, son pocos los que explicitan de qué manera ésta se produjo. Sin lugar a dudas, estos textos son previos a la aparición y diseño de una iconografía específica para el evento, que cabría datar en torno al 400, a tenor de los testimonios conservados. En el Antiguo Testamento, se hallan algunos ejemplos de ascensión que, a priori, podrían haber condicionado el relato neotestamentario. Sin embargo, y en contra de lo esperado, apenas existen concomitancias entre los textos veterotestamentarios y la narración de la Ascensión de Cristo.

El relato más detallado hace referencia a la ascensión del profeta Elías, cuando éste fue llevado a los cielos en un carro de fuego, en medio de un torbellino, ante la mirada de Eliseo, su discípulo y continuador de su misión profética: cumque pergerent, et incedentes sermocinarentur, ecce currus igneus, et equi ignei diuiserunt utrumque: et ascendit Elias per turbinem in caelum. Eliseus autem uidebat, et clamabat: Pater mi, pater mi, currus Israel, et auriga ejus. Et non uidit

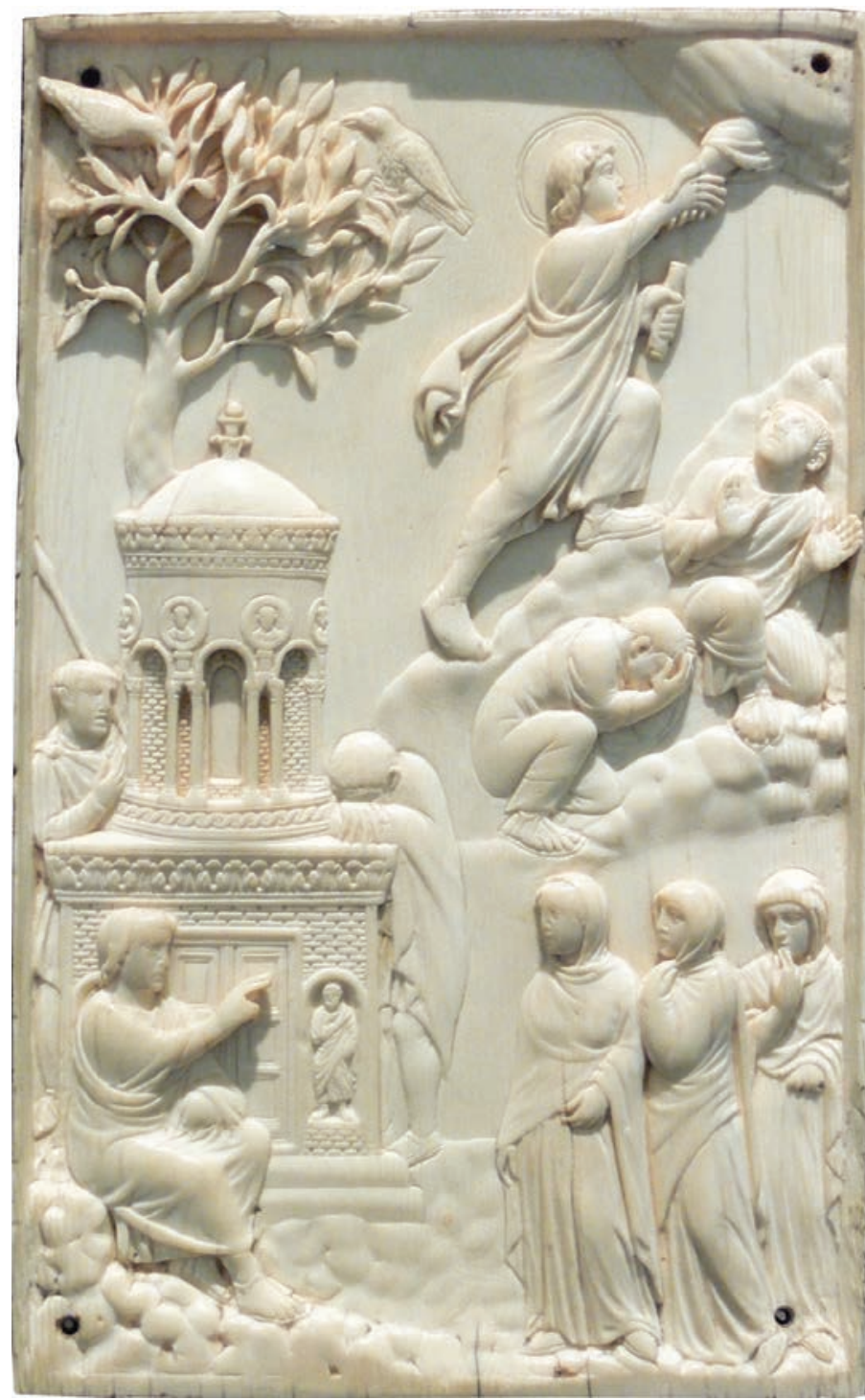

Fig. 1. Reidersche Tafel. Ascensión de Cristo, placa de marfil, Roma o Milán, c. 400. Munchen, Bayerisches Nationalmuseum. Inv.-Nr. MA 157, Foto Nr. D27841 (C) Bayerisches Nationalmuseum München

eum amplius: apprehenditque uestimenta sua, et scidit illa in duas partes. Et leuauit pallium Eliae, quod ceciderat ei: reuersusque stetit super ripam Jordanis, et pallio Eliae, quod ceciderat ei, percussit aquas, et non sunt diuisae: et dixit: Ubi est Deus Eliae etiam nunc? Percussitque aquas, et diuisae sunt huc atque illuc, et transiit Eliseus ${ }^{17}$.

En lo referente a Enoc, el relato del Génesis tan sólo indica que Dios se lo llevó sin proporcionar ningún detalle al respecto: et facti sunt omnes dies Henoch trecenti sexaginta quinque anni. Ambulauitque cum Deo, et non apparuit: quia

\footnotetext{
${ }^{8}$ Rm. 8, 34; 1Pe. 3, 22; Ef. 1, 19-20.

9 Lc. $24,50-53$.

${ }^{10}$ Ac. 1, 3-11.

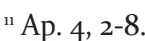

${ }^{12}$ Is. $6,1-3$.

${ }^{13}$ Ez. 1, 4-28.

${ }^{14}$ Acta Pilati, 16, 6.

${ }^{15}$ S. TSUJI, Les portes de Sainte-Sabine. Particularités de l'iconographie de l'Ascension, in CArch 13, Paris, 1962, p. 13-28.

${ }^{16}$ Euangelium Petri, 13, 55-56; vide: S. H. GUTBERLET, Die Himmelfahrt Christi in der bildenden Kunst von den Anfängen bis ins hohe Mittelalter: Versuch zur geistesgeschichtlichen Erfassung einer ikonographischen Frange, Strasbourg, 1935; S. TSUJI, art. cit. (n. 15); A. SANTOS OTERO (ed.), Los evangelios apócrifos, Madrid, 1999.

${ }^{17} 4$ Re. 2, 11-14.
} 
tulit eum Deus ${ }^{18}$. En cambio, en el apócrifo Libro de Enoc encontramos detalles más descriptivos sobre lo sucedido: "Y ocurrió después de esto que, estando aún en vida, fue asunta su persona ante ese Hijo del hombre y el Señor de los espíritus, lejos de los que moran sobre la tierra. Y ascendió en el carro del Espíritu y salió su persona de entre ellos"19. Más adelante, se añaden nuevos detalles: "Cuando el Santo, bendito sea, deseó elevarse a lo alto, envió primero a Anafiel Yahvé, el príncipe, y éste me tomó de entre ellos ante sus propios ojos y me transportó con gran gloria sobre un carro de fuego con caballos de fuego, servidores de gloria, haciéndome subir así con la Šekinah a los altos cielos"º.

Podemos ver cuan diversas son entre sí las ascensiones de estos textos. Probablemente la distancia que constatamos entre el Antiguo y el Nuevo testamento sea la misma que separa a las culturas Persa y Romana que definen respectivamente a la cultura judía de cada uno de estos momentos. Queda, pues, pendiente profundizar en esta separación, quizás a través de un ejemplo mítico como el de Alejandro Magno.

\section{EL SURGIMIENTO DEL MOTIVO DE LA ASCENSIÓN Y SU CONTEXTO LITERARIO}

Como ya se ha indicado, no es hasta finales del siglo IV cuando empiezan a documentarse las primeras imágenes del motivo de la Ascensión, tanto en Occidente como en Oriente. Ello forma parte de la lógica de una religión que, hasta inicios del siglo IV, había vivido en la clandestinidad y la proscripción sin posibilidades de desarrollar un arte público. De ahí que la Iglesia cristiana, una vez legalizada y, sobre todo, convertida en religión oficial del Imperio por obra del emperador Teodosio (edicto de Tesalónica, 27 de febrero del 380), tendiera a crear un arte áulico imitando determinados motivos propios de las temáticas iconográficas imperiales. Así sucedió, por ejemplo, en el aspecto arquitectónico, pero también en otros ámbitos artísticos. Ahora bien, cabe reconocer asimismo que una parte de la iconografía cristiana continuaba ligada a la tradición judía ya existente, la cual había encontrado la vía de manifestación natural en el contexto privado, especialmente el funerario. Tal sería el caso de temáticas sobradamente conocidas como las de Daniel en el foso de los leones, el ciclo biográfico de Jonás, los hebreos lanzados al Horno o el Arca de Noé. Sin embargo, el tema de la Ascensión u otros, como el de la Crucifixión, no aparecieron hasta una época en que el cristianismo no sólo ya no estaba proscrito, sino que estaba patrocinado y era promovido por los emperadores mismos.

El tema de la Ascensión fue tratado por algunos autores de los primeros siglos de la historia del cristianismo, pero su relato difiere bastante del de las representaciones iconográficas que se crearán siglos más tarde. Se trata de autores como Justino (199-165) ${ }^{21}$, Ireneo (130-200) ${ }^{22}$ o Tertuliano (160-220 $)^{23}$ cuya principal preocupación a la hora de escribir era la apologética y, en consecuencia, enfocaban el tema de la ascensión a los cielos desde la perspectiva de la justificación y defensa de la veracidad del hecho ante sus opositores paganos, para quienes la subida a los cielos no sólo resultaba incomprensible sino que, además, cuestionaban que pudiera haberse hecho en cuerpo y en alma.

Una vez superado el período apologético, no es hasta finales del siglo IV cuando se producen una serie de reflexiones profundas sobre el sentido de la Ascensión en autores tales como Agustín de Hipona. En sus sermones, la Ascensión es presentada como una vía de glorificación de la figura de Cristo tanto en su vertiente humana como en la divina, pues al glorificar su humanidad se abren también las puertas a la glorificación del hombre: resurrectio domini, spes Nostra; ascensio domini, glorificatio nostra ${ }^{24}$. Además, Agustín relaciona la Ascensión con el Juicio Final: Cristo se sienta a la derecha del Padre y en este gesto puede verse una transferencia de funciones jurisdiccionales ${ }^{25}$. Así pues, a través de este juicio, el hombre tiene posibilidad de redención y, de esta manera, la Ascensión puede vincularse a la salvación del hombre, por ser la acción que introduce físicamente a Cristo en el cielo: ideo enim resurrexit, ut nobis exemplum resurrectionis ostenderet; et ideo ascendit, ut nos desuper protegeret. Habemus ergo dominum et saluatorem nostrum Iesum Christum prius pendentem in ligno, nunc sedentem in caelo. Pretium nostrum dedit, cum penderet in ligno; collegit quod emit, cum sedet in caelo ${ }^{26}$. Agustín propone enlazar la Ascensión con la festividad de Pentecostés, como testimonio del fin de la misión de Cristo en la Tierra e inicio de la misión del apostolado de la Iglesia ${ }^{27}$. Ahora bien, sobre todo, la Ascensión constituye un indicio evidente de la doble naturaleza de Cristo, la humana y la divina, con lo que remarcar esta dualidad se convierte en un buen testimonio para utilizar en la lucha contra las herejías ${ }^{28}$.

Una vez entrados ya en el siglo $\mathrm{V}$, puede destacarse la reflexión sobre la cuestión de la Ascensión en León Magno (400-461), bastante en consonancia con las ideas expuestas

\footnotetext{
${ }^{18} \mathrm{Gn} .5,23-24$. op. cit (n. 3), p. 170 .

${ }^{21}$ IVSTINVS, Dialogus cum Tryphone iudaeo, 36.

${ }^{22}$ IRENAEVS, Aduersus haereses, 4, 10-11.

23 TERTVLLIANVS, De resurrectione carnis, 51.

${ }^{24}$ AVGVSTINVS HIPPONENSIS, Sermo CCLXI, 1.

${ }^{25}$ Ibidem, 7 y 10.

${ }^{26}$ IDEM, Sermo CCLXIII, 1.

${ }^{27}$ IDEM, Sermo CCLXV, 5 (6).

${ }^{28}$ IDEM, Sermo CCLXVI, 1-3.
}

${ }^{19} 1$ Enoc 70, 1-2 (traducción al español del texto original griego).

${ }^{20}$ 3Enoc 6, 1 (traducción al español del texto original griego). I. Foletti recupera el texto contenido en El libro de los secretos de Enoc, 1-3, producido en ambiente judeogreco, quizás en Alejandría, durante el siglo I dC y conservado a partir de una copia eslavónica. Según esta narración que, sin embargo, se ignora si era conocida en Roma durante el siglo V: "il profeta [Enoc] sente una grande tristeza, due angeli vengono a incontrarlo e gli annunciano che sarebbe stato assunto in cielo. Enoch saluta quindi i suoi figli e, mentre sta ancora parlando, è chiamato da due angeli e innalzato in cielo.”. Esta presencia de los dos ángeles justifica la propuesta de I. Foletti de identificar el panel de Santa Sabina con la ascensión de Enoc. (cf. I. FOLETTI, M. GIANANDREA, 
por Agustín. León insiste en la Ascensión como instrumento de "depuración" de la naturaleza humana al ser aceptada en los cielos la forma humana de Cristo: illius gloriae sociaretur in throno, cuius naturae copulabatur in filio. Quia igitur Christi ascensio, nostra prouectio est, et quo praecessit gloria capitis, eo spes uocatur et corporis, dignis, dilectissimi, exsultemus gaudiis, et pia gratiarum actione laetemur ${ }^{29}$. Y en otro de sus sermones, vuelve a poner en relación la Ascensión con la glorificación y la redención del ser humano ${ }^{30}$, especialmente en el pasaje siguiente: tunc igitur, dilectissimi, filius hominis, dei filius, excellentius sacratiusque innotuit, cum in paternae maiestatis gloriam se recepit et ineffabili modo coepit esse diuinitate praesentior, qui factus est humanitate longinquior ${ }^{31}$.

Podría decirse, pues, que iconografía y exégesis avanzaron conjuntamente, apareciendo en un mismo momento. En cierto sentido, una vez superado el período de la apologética antipagana, la aparición de una serie de intelectuales romanos en el panorama ideológico de la Iglesia cristiana, punto de inflexión lógico en un proceso de oficialización con todas las consecuencias, comportó adaptar el repertorio iconográfico "romano" a los nuevos temas requeridos por el contexto del momento, tales como la Ascensión. Por otra parte, fue también en este momento cuando la festividad de la Ascensión empezó a definirse hasta encontrar un lugar propio entre los años 380 y $450^{32}$.

\section{LAS DIFERENCIAS ICONOGRÁFICAS ENTRE OCCIDENTE Y ORIENTE}

Sin embargo, el Imperio de los siglos III-V distaba mucho de ser el espacio unificado que soñara Augusto y, en el lenguaje adoptado por la figuración, existía una clara escisión entre Occidente y Oriente. Paradójicamente (o, mejor, precisamente), esto se produce en un momento en que la Iglesia intenta definir unos elementos ideológicos comunes mínimos en lo que había sido un crecimiento orgánico, durante los cuatro primeros siglos. La diferencia esencial entre las dos partes del Imperio podría justificar las variantes compositivas entre las dos tipologías de ascensiones desarrolladas entre los siglos Vy VI, bastante distintas entre sí.

Por un lado, la que consideramos como "tipología occidental" presenta la figura de Cristo subiendo, de modo más o menos realista, una pendiente montañosa, a veces culminada por la dextera Domini. Como testimonios del suceso, un grupo reducido de apóstoles se tapan la cara con las manos o se echan al suelo de manera dramática y expresiva. Esta fórmula difiere bastante de la descrita en los Hechos de los apóstoles, citada previamente. Sin embargo, lo más pro-

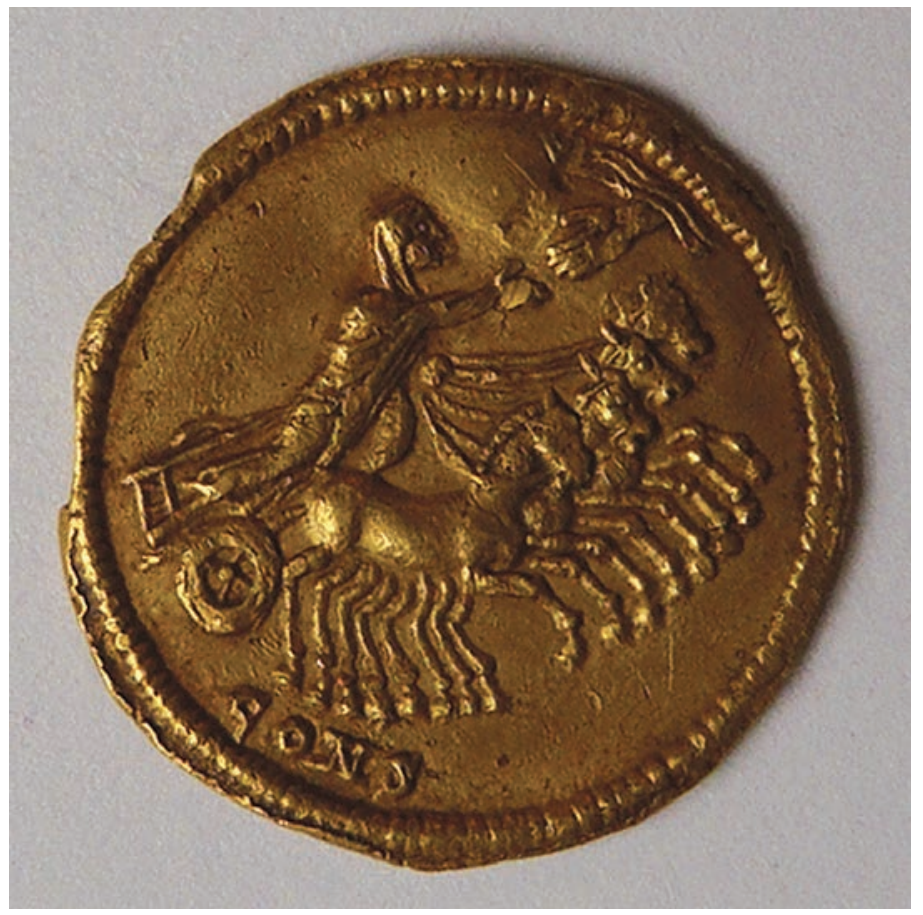

Fig. 2. Moneda de la ascensión de Constantino, Constantinopla, 337. París, Bibliothèque Nationale de France. Fotografía: (C) Département des Monnaies, Médailles et Antiques. Bibliothèque Nationale de France.

bable es que el modelo iconográfico para esta escena sea la moneda de la apoteosis de Constantino I acuñada en el 337 en numerosas cecas, tanto de Oriente como de Occidente (fig. 2). En ella, Constantino, ya difunto, asciende hacia los cielos en un carro y se dirige hacia una mano que sale de los cielos para acogerle de manera prácticamente idéntica a la de la tabla Reidersche de Munic (ca. 400)33. Sin embargo, y a pesar de las semejanzas estéticas entre ambas piezas, existe una diferencia conceptual muy importante entre ellas, pues en la moneda del 337, la mano significa la inclusión de Constantino I en el coetus diuorum celestial, mientras que en la placa ebúrnea cristiana la idea es la de recibir a Cristo, de regreso a la morada celestial que abandonó cuando se encarnó como hombre en el vientre de la Virgen María.

Por otro lado, la que hemos denominado como "tipología oriental”, normalmente, presenta una división en dos registros. En el superior, perteneciente al mundo celestial, se muestra a Cristo, entronizado o no, pero en plena demostración de su majestad, acompañado de ángeles y, en ocasiones, de las figuras del tetramorfo. En el inferior, perteneciente al mundo terrenal, se presenta a los testimonios de la Ascensión, es decir, el grupo completo de los apóstoles acompañados, de manera muy recurrente, de la

\footnotetext{
${ }^{29}$ LEO MAGNVS, Sermo LXXIII, 4.

${ }^{30}$ IDEM, Sermo LXXIV, 1-4; vide Y. CHRISTE, op. cit. (n. 4); G. SCHILLER, Ikonographie der christlichen Kunst, Gütersloh, 1966; S. H. GUTBERLET, op. cit. (n. 16).

${ }^{31}$ LEO MAGNVS, Sermo LXXIV, 4.

${ }^{2}$ T. DEWALD, art. cit. (n. 4), p. 277.

${ }^{33}$ H. B. MATTINGLY et alii, The Roman imperial coinage, VII: Constantine and Licinius (A.D. 313-337), London, 2003, p. 446. El motivo de la mano surgiendo de una nube, aunque una novedad en la imaginería de las apoteosis imperiales, no era nuevo en la iconografía constantiniana, pues éste lo había usado ya en una medalla que hoy se encuentra en el Kunsthistorisches Museum de Viena, datada entre 330 y 333, que muestra al emperador rodeado por los tres Césares y bajo una mano saliendo de una nube que lleva en su mano una diadema (J. Bardill, Constantine, divine emperor of the Christian golden age, Cambridge, 2012, p. 378). Tampoco era una novedad en el imaginario romano, ya que, por ejemplo, una imagen parecida es descrita por Suetonio (De Vita Caesarum, 1 , 81) al narrar un sueño premonitorio de la muerte de Julio Cesar. Así mismo puede tener un vínculo de transmisión iconográfica con de Dextrarum Iunctio. La ascensión en carro a los cielos también goza de una amplia tradición iconográfica romana, por ejemplo, en diversas monedas de la dinastía Antonina y, sobretodo, en el famoso "Monumento de los partos", erigido en Éfeso ca. 169 (hoy en día en el Ephesos Museum de Viena), donde Lucio Vero, ya difunto en aquel momento, es mostrado en el momento de subirse al carro que le conducirá a los cielos acompañado del Sol.
} 
figura de la Virgen en posición orante. De esta manera, la tipología oriental se muestra más atemporal y teofánica, a la vez que resume de forma más literal las descripciones neotestamentarias sobre la Ascensión ${ }^{34}$.

Uno de los elementos de la iconografía de la Ascensión que quedó claramente justificado por razones doctrinales fue la aparición de la Virgen. Ello nos permite suponer que la diferente caracterización iconográfica entre Oriente y Occidente constituyó un reflejo de las diferentes tendencias teológicas entre las diversas iglesias cristianas, cada una con sus propias emisiones iconográficas que debían superarse para poder culminar la política de unificación doctrinal iniciada a inicios del siglo IV. La Virgen, tal como la encontramos, por ejemplo, en el evangelio de Rábula, sólo se explica en relación con la polémica sobre la doble naturaleza de Cristo y de la maternidad de la Virgen María como Theotokós (sancionada en el concilio de Calcedonia del 451).

El momento culminante de la fijación doctrinal de la Ascensión encuentra en el credo de Nicea su texto fundacional (325), convocado y presidido por Constantino I. Fue en este sínodo donde se definió la ortodoxia conocida cómo "símbolo niceno" (o credo de Nicea). En él, se insiste en la subida a los

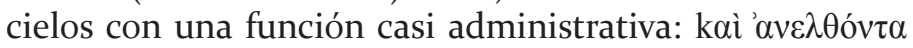

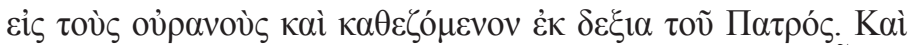

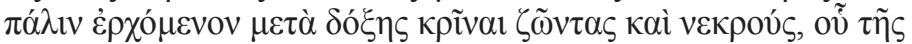

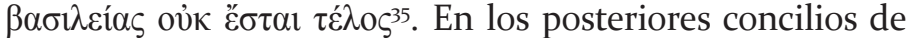
Sárdica (343) y de Constantinopla (381) no sólo se ratificó el símbolo niceno, sino que, además, la Ascensión se consolidó como verdad teológica. Resulta difícil sustraerse a la idea de que esta decisión, tomada en un concilio convocado y dirigido por el emperador Constantino I no tuviera relación alguna con el poder imperial. Es más, probablemente, el reconocimiento oficial que se desprende de esta "apoteosis" de Cristo estaría relacionado con una necesidad de legitimación mutua, pues según las narraciones cristianas de escritores de época constantiniana, caso del De mortibus persecutorum de Lactancio o la Vita Constantini de Eusebio de Cesarea, la victoria de Constantino I en el Puente Milvio contra el usurpador Majencio (312) había sido una concesión de la divinidad cristiana para concederle a aquél las riendas del Imperio.

\section{ASCENSION VS APOTEOSIS}

Ya en su momento E. T. Dewald propuso que "in any case the apotheosis offered a convenient mould in which the Christian artist could fit the data afforded by the canonical or apocryphal accounts of the Ascension, and it seems likely that we have here the ultimate source of the Hellenistic type"36. Y, en el mismo sentido, V. M. Schmidt, en su reciente entrada sobre la Ascensión en la Enciclopedia

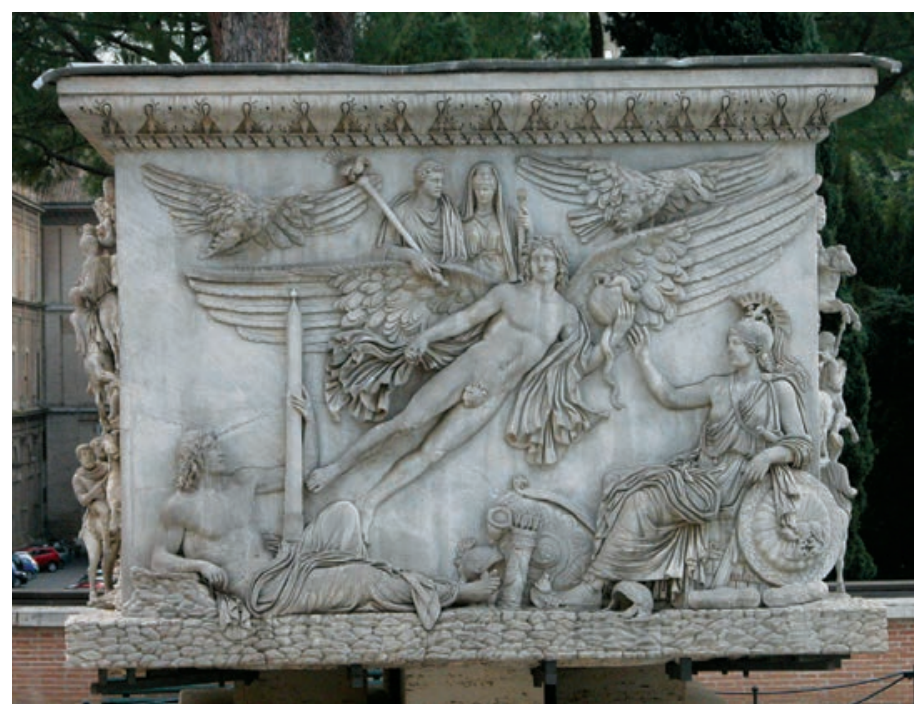

Fig. 3. Apoteosis de Antonino Pío y Faustina, base de la columna de Antonino, Roma; 161-162 n.e. Città del Vaticano, Musei Vaticani. Fotografia: ArxiuCMancho

dell'Arte Medievale afirma: "i primi artisti che rappresentarono l'Ascensione utilizzarono l'iconografia classica delle assunzioni e, in particolare, quella dell'apoteosi" 37 . Por todo ello, la historiografía ha considerado que la relación entre la apoteosis y la Ascensión es evidente y, a la pregunta de si hay una relación directa entre ambas, la respuesta ha sido siempre afirmativa ${ }^{3}$.

En realidad, lo que constata nuestro análisis es que la relación entre una y otra es menos evidente pero, quizás por ello, más estructural, pues no remite a la forma sino al fondo: la idea de la asunción de la divinidad mediante una subida a los cielos. En el momento en que los cristianos, reconocidos oficialmente y apoyados por el emperador, tuvieron que monumentalizar sus lugares de reunión tuvieron ante ellos diversas posibilidades. Si bien hubiera resultado razonable "usurpar" el modelo de la sinagoga, ello no habría permitido distinguir entre una y otra comunidad; por otro lado, habrían podido continuar usando el modelo de templo romano, pero ello hubiera supuesto, en términos sociales, una asimilación al resto de cultos. Para las iglesias del siglo IV se acabó adoptando, como modelo, la basílica; es decir el tipo de edificio administrativo por excelencia que, como todo en la antigua Roma, estaba impregnado por el culto oficial, pero no era un lugar específicamente religiosoy, además, constituía una de las mayores expresiones de la edilicia imperial. Así pues, las primeras iglesias paleocristianas no se parecieron a un templo, aunque lo eran.

Pues bien, como en las iconografías de las apoteosis imperiales ${ }^{39}$, caso de la de Tito o la de Antonino Pío (fig. 3),

\footnotetext{
${ }^{34}$ G. SCHILLER, op. cit. (n. 4); H. L. KESSLER, Scenes from the Acts of the apostles on some early Christian ivories, in Gesta, 18/1, Chicago, 1977-1978, p. 109-119. 35 Tradicionalmente, el pasaje se traduce como: "subió a los cielos, vendrá a juzgar a los vivos y a los muertos". En el concilio de Constantinopla (381), se dice: "subió al cielo, y está sentado a la derecha del Padre. Y de nuevo vendrá, en gloria, para juzgar a vivos y a muertos, y su reino no tendrá fin" (I. ORTIZ, El símbolo niceno, adrid, 1947, p. 23).

${ }^{36}$ T. DEWALD, art. cit. (n. 4), p. 281-282.

37 V. M. SCHMIDT, art. cit. (n. 4), p. 573

${ }^{38}$ Vide T. DEWALD, art. cit. (n. 4), p. 277-319; S. H. GUTBERLET, op. cit. (n. 16); K. WEITZMANN, The survival of mythological representation in early Christian and Byzantine art and their impact on Christian iconography, in DOP 14, Washington 1960, p. 43-68; A. GRABAR, L'empereur dans l'art byzantin, London, 1971; B. BRENK, The imperial heritage of early Christian art, in K. Weitzmann (ed.), Age of spirituality: late antique and early Christian art, New York, 1980, p. 39-52; G. M. A. HANFMANN, The continuity of classical art: culture, myth and faith, in ibidem, p. 75-100; A. GRABAR, Las vías de la creación en la iconografía cristiana, Madrid, 1985; T. F. MATHEWS, The clash of gods: a reinterpretation of early Christian art. Princeton, 1993.

39 Vide P. GROS, Rites funéraires et rites d'immortalité dans la liturgie de l'apothéose impériale, in Annuaire de l'École Pratique des Hautes Études. IVe section: Sciences Historiques et Philologiques 1965-1966, p. 477-490; J. ARCE, «Funus imperatorum»: los funerales de los emperadores romanos, Madrid, 1988; S. G. MacCORMACK, Art and ceremony in the late antiquity, Berkeley, 1990.
} 
la Ascensión cristiana nos habla del "emperador" (es decir, Cristo), que sube para reunirse con el Padre y, para ello, es ayudado bien por la dextera Domini, bien por ángeles, del mismo modo que en las iconografías de la consecratio imperial el alma era ayudada por diversos tipos de mensajeros divinos (águila, aion, erotes, carro, victorias, etc.), un elemento sobrenatural que constituye un elemento esencial en el proceso de divinización. El hecho de que, a partir de finales del siglo III, el emperador fuera considerado un dios en la Tierra no hacía sino simplificar la asociación metafórica entre el Cristo y el emperador.

El segundo elemento esencial compartido entre las apoteosis imperiales y las ascensiones es el testigo. Las diferencias entre ambos prototipos iconográficos son evidentes, pues en las ascensiones cristianas siempre se trata del mismo colectivo, los discípulos, aún cuando se constaten diferencias entre los modelos occidental y oriental. Con todo, a pesar de las divergencias, cualquier romano que contemplara una escena de ascensión cristiana no habría dudado ante lo que estaba viendo: una apoteosis en la que un personaje se elevaba por encima de los demás ante la mirada de un testigo que daba testimonio de ello.

Lo más sorprendente, en cualquier caso, es la gran diferencia entre las configuraciones occidental y oriental, la cual, como pasa a menudo, resulta mucho más estable ${ }^{40}$. Mientras en Occidente, la Ascensión cristiana es más realista y menos literal respecto al texto de Hechos de los apóstoles, 1, 3-11, en Oriente, toma como base el texto bíblico pero la iconografía resulta más especulativa, pues tanto lo que se representa en Bawit como en Jerusalén o en Rábula también tiene mucho quever con el mensaje de Ezequiel y de la Parusía. Además, la presencia de la Virgen remite al carácter físico de la apoteosis cristiana. La escena pasa, así, de ser narrativa y de trasladar a imágenes el relato de Hechos de los apóstoles, a sintética, pues la presencia de la Theotokós sirve de paráfrasis para exponer la doble naturaleza de Cristo.

En Occidente, sin embargo, quizás se trató de recordar la apoteosis física. No es extraño, pues, que las piezas oc- cidentales muestren la "escalada" física de Cristo. Además, que de ello se derive una conexión visual con Moisés y el Sinaí es uno de los múltiples juegos de espejos literarios que pudo permitirse quien en su día concibiera esta imagen. Sin embargo, la presencia de los dos elementos básicos que són la ayuda divina en la ascensión (la dextera Domini) y los testigos, situaban a cualquier observador ocasional ante la misma realidad iconográfica: la apoteosis. De todo ello, pues, puede inferirse con G. Schiller que la relación entre la apoteosis imperial y la Ascensión cristiana era de tipo conceptual, si bien esta autora no desarrollara a fondo la idea ${ }^{41}$. Es por ello, quizás, que mientras los paganos se referían a la apoteosis imperial mediante los términos apotheosis (de origen griego) o consecratio in forma deorum (denominación en latín), los apologetas y los padres de la Iglesia de los siglos IV-VI preferían ascensio Domini. Con ello, en nuestra opinión, además de marcar una diferencia de léxico respecto a una práctica eminentemente pagana, se superaba además un inconveniente conceptual al aplicar el término "apoteosis" a la Ascensión de Cristo, pues se hubiera usado un término que aludía a la conversión en dios de quien antes era un hombre, para Cristo, del cual se pretendía la divinidad desde la encarnación como hombre en el vientre de la Virgen María manteniendo unidas sus dos naturalezas -tal y como gráficamente exhiben las ascensiones orientales-.

En nuestra opinión, la Iglesia de la ciudad de Roma, especialmente, a finales del siglo IV, sintió la necesidad de asociar a Cristo con el concepto de emperador a través de una adaptación general de la iconografía imperial, dentro de un proceso de substitución de la estructura administrativa del Imperio por la de la Iglesia, tal como puede tan bien observarse, por ejemplo, en el mosaico de la iglesia de Santa Pudenciana (siglos IV-V). La cristianización de la iconografía de la apoteosis imperial por parte de la Iglesia se convierte así en un elemento básico en el esfuerzo por legitimar la apropiación paulatina de toda la estructura imperial.

\footnotetext{
$4^{\circ}$ Así puede constatarse, por ejemplo, en la temática de la Crucifixión C. MANCHO, "La crucifixion de Saint-Pierre de Sorpe et le crâne d'Adam au Golgotha: la complexité de la peinture mural romane pyrénéenne”, La peinture murale à l'époque romane, París, 2016, p. 159-173 (XLVIIes Journées romanes de Cuxa). ${ }^{41}$ G. SCHILLER, op. cit. (n. 4), p. 144.
} 